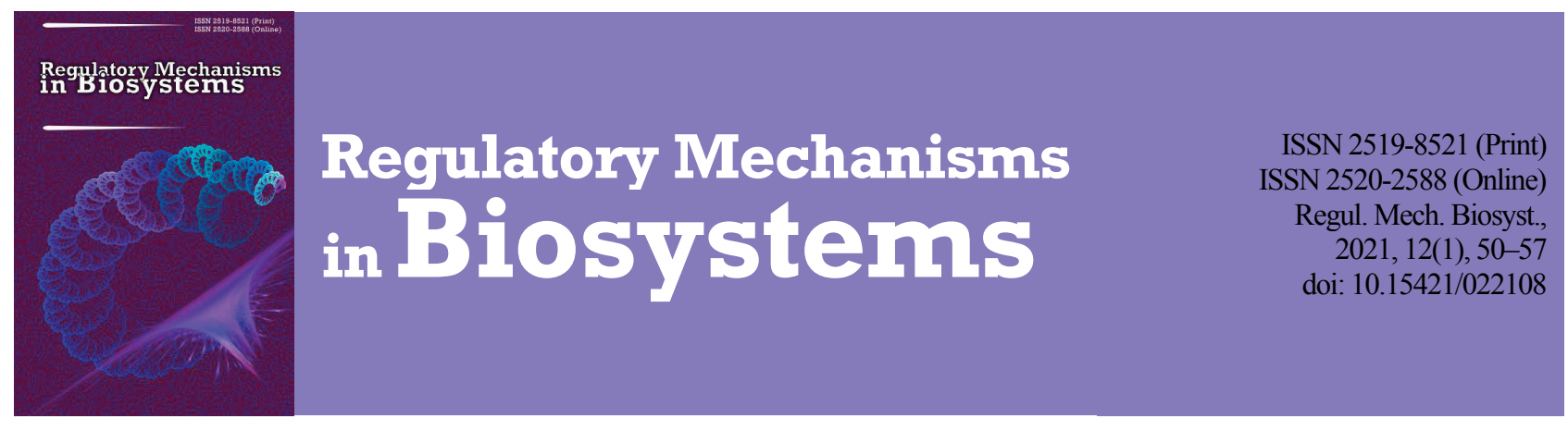

\title{
Regional anesthesiological support for the implementation of surgical interventions in the abdomen of dogs
}

\author{
D. V. Sliusarenko*, M. G. Ilnitskiy**, D. D. Bilyi***, O. M. Bobrytska*, L. O. Kovalova**** \\ *Kharkiv State Zooveterinary Academy, Mala Danylivka, Ukraine \\ **Bila Tserkva National Agrarian University, Bila Tserkva, Ukraine \\ ***Dnipro State Agrarian and Economic University, Dnipro, Ukraine \\ ****Polissia National University, Zhytomyr, Ukraine
}

Article info

Received 12.01.2021

Received in revised form 06.02.2021

Accepted 08.02.2021

Kharkiv State Zooveterinary Academy, Academic st., 1, Mala Danylivka, Derhachi district, Kharkiv region 62341

Ukraine. Tel.: +38-066-215-58-05.

E-mail: slusarenkodmitriy@gmail.com

Bila Tserkva National Agrarian University, Soborna sq., 8/1, Bila Tserkva, 09117, Ukraine. Tel.: +38-067-595-38-15. E-mail: ilnitskyl@rambler.ru

Dnipro State Agrarian and Economic University, S. Efremovst., 25 ,

Dnipro, 49600, Ukraine.

Tel.: +38-050-361-38-30.

E-mail:_mdmbeliy@i.ua

Polissia National University, Staryi Blvd, 7, Zhytomyr, 10008, Ukraine.

Tel.: +38-067-391-47-92. E-mail: ludmilagudimenko85@gmail.com

\begin{abstract}
Sliusarenko, D. V., Initskiy, M. G., Bilyi, D. D., Bobrytska, O. M., \& Kovalova, L. O. (2021). Regional anesthesiological support for the implementation of surgical interventions in the abdomen of dogs. Regulatory Mechanisms in Biosystems, 12(1), 50-57. doi:10.15421/022108
\end{abstract}

Widespread use of surgical interventions in the abdomen of dogs determines the relevance of the study. The research tested the influence of therapeutic epidural blockade with $0.2 \%$ bupivacaine after surgical interventions on the background of potentiated local anaesthesia on the body of clinically healthy dogs undergoing ovariohysterectomy. In the control group postoperative analgesia was performed with the nonsteroidal anti-inflammatory drug rimadyl on the background of potentiated thiopental anaesthesia. Wound healing rates were determined in 10 animals of both control and experimental groups; blood counts and the level of inflammatory response were indicated in 5 animals of each group. The dynamics of reparative processes and complete wound healing in dogs of the experimental group occurred earlier than in animals of the control group, which confirmed the fact that the use of bupivacaine had a beneficial effect on tissue regeneration. The results of morphological and biochemical parameters of blood in animals of the experimental group manifested only an increase of leukocytes by 1.58 times, fibrinogen by 2.02 times, while in dogs of the control group the level of erythrocytes, haemoglobin and hematocrit decreased, leukocytes increased by 1.74 times, platelets decreased by 2.87 times and fibrinogen increased by 1.72 times. Among the stress response markers in the control group there was a 1.94 times increase in glucose level after surgery. In the experimental group there was a decrease in the intensity of the inflammatory reaction in dogs, accompanied by an increase of anti-inflammatory interleukin 4 (IL-4) only on the seventh day - 1.86 times, while in the control group the level of anti-inflammatory interleukin 1 receptor antagonist (IL-1RA) after three days increased by 2.30 times, after seven days - by 2.48 times, and the level of proinflammatory interleukin 6 (IL-6) after surgery increased by 2.57 times. It will be promising to conduct further research on the influence of therapeutic blockades with bupivacaine in animals in cases of various surgical interventions and pathological conditions, which will lead to faster recovery of animals and alleviate pathological processes.

Keywords: epidural blockade; local anaesthetics; bupivacaine; wound healing; stress markers; cytokines.

\section{Introduction}

Pain management in veterinary patients is a crucial component of appropriate patient care (Grubb \& Lobprise, 2020). Traditional methods of anesthesia for animals do not always provide full antinociceptive protection of the body, which is why in modern conditions a search to improve pain relief schemes continues. The sign of effective analgesia is influence on the nervous system that helps to alleviate the course of disease as a whole, as well as surgical intervention and the postoperative period. Anesthetic support is more effective when it is performed during the period when the animal can feel nociceptive stimulation.

Pain relief can be achieved with multicomponent analgesia with differentiated use of drugs of different pharmacological groups, depending on pathogenesis of the pain syndrome, the condition of the animal, the volume and trauma of surgery. Nowadays, there are many options for the use of analgesics of different pharmacological groups, such as epidural morphine in dogs (Carregaro et al., 2016), magnesium sulfate (Bahrenberg et al., 2015), in the case of blockade of the brachial plexus in lambs a mixture of local anaesthetics, morphine and tramadol (Ghadirian et al., 2016). A combination of $0.1 \mathrm{~mL}$ buprenorphine and $0.3 \mathrm{~mL} 0.5 \%$ bupivacaine for infraorbital nerve blocks provided analgesia for $>24$ hours in some dogs (Snyder \& Snyder, 2016). It is commonly accepted that local and regional administration of drugs, when compared with systemic bolus administration, generally results in a lower incidence of dose-related adverse effects. Lidocaine is the only local anaesthetic that can be administered systemically (Grubb \& Lobprise, 2020). The toxic effects of local anaesthetic are covered in more detail in some reports (Rioja Garcia, 2015). The use of local anaesthetic in certain doses may cause systemic toxicity, which must be indicated for different medicines. Due to their ability to profoundly decrease both intraoperative nociception and postoperative pain, local anaesthetic drugs are recommended for use in the majority of surgical procedures and traumatic injuries, as outlined in recent veterinary pain management guidelines (Epstein et al., 2015). However, the latest anaesthetic discoveries in veterinary medicine are not fully used in Ukraine. The reason is the lack of access to many drugs and the inertia of veterinarians in implementing new anaesthetic methods. At the same time, there is a number of innovative approaches that can improve the anaesthesiological support of surgical care, such as: the ability of local anaesthetics to cause analgesia and autonomic blockade, postoperative analgesia, repeated administration of the drug along with nerve structures.

As a rule, in animals local anaesthesia is performed to eliminate sensitivity to surgery, as a means of novocaine pathogenetic therapy (Vlasenko 
\& Tyhonjuk, 2000; Kerroll, 2009; Butterworth, 2010), as well as for diagnostic purposes. This list can be supplemented by postoperative analgesia. There are different ways to perform this with the help of drugs of different pharmacological groups, in particular alfaxone, a combination of ketamine with detomidine in cats (Kalchofner Guerrero et al., 2014), intravenous infusion of lidocaine, fentanyl, ketamine, dexmedetomidine (GutierrezBlanco et al., 2015), as well as mixtures of morphine, lidocaine and tramadol (Mastrocinque \& Fantoni, 2003; Wendt-Hornickle et al., 2016) in dogs. At the same time, the most effective methods of local anaesthesia are those performed on the large nerves, nerve trunks and roots of the spinal nerves, which include epidural and conduction blockade. Nowadays, for epidural anaesthesia in dogs such local anaesthetics as lidocaine (Son et al., 2015), bupivacaine epidurally (Son et al., 2014) and subarachnoidally (Sarotti et al., 2015), ropivacaine peribulbarly (Wagatsuma et al., 2014), bupivacaine and ropivacaine for conductive blockade of the humeral plexus in dogs (Wakoff et al., 2014) are used both in experiments and in clinical practice. Sometimes, in addition to local anaesthetics, drugs of other pharmacological groups, such as lidocaine and tramadol separately and in mixture for donkeys are used epidurally (Marzok \& Elkhodery, 2015).

It is known that epidural and conduction blockades with local anesthetics cause many physiological responses from the nervous, respiratory, cardiovascular, urogenital, and gastrointestinal tracts that should not be considered only as a pain relief effect (Subbotin et al., 2000; Butterworth et al., 2010). These effects can be used as a part of an integrated treatment of the animal during surgery and as postoperative analgesia. If surgery is not performed, but there is nociceptive irritation, therapeutic epidural or conduction blockade can also be performed to provide analgesia or therapeutic effect (Subbotin et al., 2000). At the same time, in modern conditions the appropriate anaesthesia care for animals is possible due to the introduction of new drugs and technical means for local anaesthesia (Kerroll, 2009; Butterworth, 2010; Hansen et al., 2013; Koch et al., 2016; Sljusarenko et al., 2016). High-technology support of local anaesthesia helps reduce the number of failures and complications in its implementation.

The introduction of new local anaesthetics into veterinary practice should be preceded by their comprehensive study. The species, breeds and individual characteristics of animals, as well as the purpose, type of local anaesthesia or analgesia should be also taken into account. Novocaine and lidocaine are the most commonly used drugs in veterinary medicine, but they do not provide long-term action. Thus, the most promising drugs of long-term action (Orlov, 2011) are bupivacaine and ropivacaine (Morgan $\&$ Maged, 2000). With a single injection of modern amide local anaesthetics, the analgesic effect can last for 4-8 hours, and the mean elimination half-life of bupivacaine was $8.75 \mathrm{~h}$ (Trabelsi et al., 2017). One of the effective technical means of epidural anaesthesia is catheterization of the epidural space. In human medicine catheter fixation in body tissues has been used for a long time (Bomberg et al., 2016). To prevent microbial contamination a bacterial filter (Senera et al., 2015), is applied, which can be successfully used in animals. There are also reports concerning the use of neurostimulation to determine the position of the needle in the epidural and subarachnoid space in dogs (Otero et al., 2014) and in the epidural space in cats (Otero et al., 2014), as well as ultrasound visualization of the position of the needle in the epidural space in animals (Johns et al., 2014; Viscasillas et al., 2014). An important issue of veterinary anesthesiology is also the determination of physiological parameters, hematological parameters and metabolic parameters, in particular the level of stress response of the body (Romano et al., 2016) in the process of surgical treatment. According to the results of the study of the mentioned author, local anaesthesia was less stressful than the use of opiates.

Therefore the objective of this study was the scientific substantiation of epidural blockade schemes, which are based on the knowledge of their mechanism of action and influence on the physiological parameters of the animal, blood parameters, degree of inflammatory reaction, anti-stress effect for dogs.

\section{Materials and methods}

The research was conducted in accordance with the requirements of "The European Convention for the Protection of Vertebrate Animals"
(Strasbourg, 1986) and the Law of Ukraine "On the Protection of Animals against Cruelty" (2006), which was confirmed by the conclusion of the Bioethics Commission of Bila Tserkva National Agrarian University.

Clinical studies were conducted on clinically healthy female dogs, which underwent ovariohysterectomy at the Department of Surgery named after Professor I. O. Kalashnyk at Kharkiv State Zooveterinary Academy and at the Department of Surgery and Diseases of Small Animals at Bila Tserkva National Agrarian University from 2015 to 2019.

The research compared the effect of therapeutic epidural blockade with $0.2 \%$ solution of bupivacaine and traditional methods of medication influence, studied clinical and biochemical parameters of blood to determine the nature of inflammatory and stress reactions, as well as the dynamics of metabolism and wound healing in clinically healthy dogs undergoing ovariohysterectomy. In the dogs ovariohysterectomy was performed using two schemes of surgical and postoperative analgesia. Animals of the control group received an anaesthetic regimen available in modern conditions - xylazine-potentiated intravenous thiopental anaesthesia with thiopenate and postoperative analgesia with the nonsteroidal anti-inflammatory drug rimadyl once a day at a dose of $1 \mathrm{~mL}$ per $12.5 \mathrm{~kg}$ of body weight intramuscularly. This regimen was chosen due to the availability of these drugs to most veterinarians.

In the experimental group premedication with xylazine, epidural puncture, catheterization, anaesthesia with $2 \%$ lidocaine solution, postoperative analgesia with $0.2 \%$ bupivacaine solution were performed for three days. To perform epidural anaesthesia we used disposable kits "Perifix", which consisted of a Tuohy needle, a syringe to test the position of the needle, catheter, adapter and bacterial filter. The local anaesthetic was administered through a catheter, which after its placement was fixed by the "tunneling" method, and during the operation it was additionally closed outside with band aid. This catheter fixation was used when the animal was fixed on the table in a supine position. After the operation the band aid was removed and the catheter was left in the thickness of the tissue.

During the operation a laparotomy was performed along the white line of the abdomen in the extraumbilical area. During the final stage of the operation suture material polyamide No. 4 was used. Sutures were applied as follows: the first layer of the suture - on the peritoneum, transverse fascia, internal and external aponeurosis of the rectus abdominis; continuous mattress suture - on the subcutaneous tissue, continuous twolayered internal - on the subcutaneous tissue. After suturing, the edges of the wound were pressed together. The seams were not removed. At the end of the operation all animals underwent antibacterial therapy using the antibiotic "Combikel LA" at a dose of $1 \mathrm{~mL}$ per $10 \mathrm{~kg}$ of body weight of the animal, once, subcutaneously, infiltratively, parallel to the surgical wound on both sides.

The effectiveness of two anaesthesia regimens for canine ovariohysterectomy was studied according to two criteria - determining the nature of the surgical wound healing and the study of blood parameters.

Wound healing in dogs after ovariohysterectomy was determined according to the following parameters: the condition of the wound edges, especially the presence of tissue edema around the wound, the beginning and the end of wound epithelialization, the period of complete wound healing, the percentage of wound healing by primary tension. Surgical wound healing was studied on 20 clinically healthy dogs, 10 dogs in each group - experimental $(n=10)$ and control $(n=10)$.

Blood samples from animals of the experimental $(n=5)$ and control $(n=5)$ groups were taken from the jugular vein before anaesthesia and operation, after surgery, three, seven and ten days after surgery. Clinical analysis of blood was performed using a veterinary hematology analyzer "Mindray BC-2800 VET" (Mindray, China). The number of erythrocytes, leukocytes, platelet count, hemoglobin, hematocrit, lymphocytes, monocytes and granulocytes were determined in the selected samples.

Serum and plasma biochemical studies were performed using a semiautomatic biochemical analyzer "Stat Fax 1904" (Awareness Technology, USA), a semi-automatic enzyme-linked immunosorbent assay "Stat Fax 303+" (Awareness Technology, USA) and a coagulometer "K-3002 Optic" (Kselmed, Poland). Serum and plasma levels of total protein, urea, creatinine, glucose, C-reactive protein, fibrinogen, cortisol and IL-1 RA, IL-4, IL-6 interleukins were determined. Glucose and cortisol levels were 
determined as markers of the level of the body's stress response to the performed manipulations.

The level of urea was determined by UreUV-DAC kinetic method, creatinine - by JAFFE kinetic method with alkaline picrate ("Dialab", Austria), glucose - by glucose oxidant method ("Filicit-Diagnostic", Ukraine), cortisol - by the method of solid-phase enzyme-linked immunosorbent assay ("Hema", Russia), the level of fibrinogen was studied by DIA-FIB Klaus method ("Diagon", Hungary). In addition, the level of inflammatory response in the animals was determined by IL-1 RA, IL-4, IL-6 interleukins using the method of solid-phase enzyme-linked immunosorbent assay and diagnostic kits of LTD "Vector-Best", Ukraine on "Statfax 303 Plus" photometer.

Statistical processing of the results was performed using Statistica 10 (StatSoft Inc., USA, 2011). The experimental data analysis was performed using the ANOVA method. Differences between the values were considered reliable at $\mathrm{P}<0.05$ (taking into account the Bonferroni correction). The numerical data in the tables are presented as $\mathrm{x} \pm \mathrm{SD}$.

\section{Results}

An important aspect of epidural anaesthesia is the identification of the needle position in the epidural space, which prevents failures and complications (subarachnoid and intravascular administration of local anesthetic) during the blockade. The relevance of this issue is due to the fact that in the literature there are no recommendations for tests to control the position of the needle, which would take into account the species and size of the animal, and it contains only general data. An important factor that should be taken into account during an epidural puncture is the anatomical and physiological patterns on the basis of which identification tests are performed. They include:

- the puncture needle passes through tissues that have different densities;

- the intercostal ligament is denser than all other tissues, and its puncture and penetration of the end of the needle into the epidural space is felt as overcoming a kind of obstacle;

- in the epidural space the pressure is less than atmospheric.

All tests of epidural space identification are based on these features. The most well-known ones are the "loss of resistance" test and the "suspended drop" test.

The "loss of resistance" test is performed in two ways. The first one supposes that the needle is held by hand during the puncture of the tissues. When the intercostal puncture is performed, there is a feeling of the needle's penetration, which is usually quite well defined. In the second method a special syringe is connected to the puncture needle, which is part of the "Perifix" kit, while the needle is slowly pushed inwards with the left hand, and the plunger of the syringe is constantly pressed with the right hand. When the end of the needle enters the epidural space, the resistance decreases sharply, and the syringe plunger moves easily. We found that the first method is more convenient, and we used it in research.

The "suspended drop" test is performed by placing a small amount of local anaesthetic on the needle cannula, which is visually similar to a drop that disappears when the intercostal ligament is punctured by moving the drug inward due to reduced pressure in the epidural space. We used this test as an auxiliary one. The final criterion for the correct position of the needle in the epidural space was the free movement of the catheter in the cranial direction. The end of the catheter was placed at the level of the fifth lumbar vertebra of the animal.

Surgical wound healing after ovariohysterectomy in dogs which underwent operative and postoperative local anaesthesia regenerative processes occurred faster than in animals treated with anaesthesia and rimadyl administered after surgery. The animals of the experimental group had better dynamics of reparative processes, which was manifested with earlier $(\mathrm{P}<0.001)$ filling of the wound with epithelial tissue - after $4.83 \pm$ 0.25 days compared with the control group $-7.72 \pm 0.37$ days. Complete wound healing in the experimental group occurred earlier $(\mathrm{P}<0.001)$ after $7.07 \pm 0.26$ days compared with the control group $-10.24 \pm$ 0.25 days. The wound area that healed by primary tension in the experimental group was larger than in the control group $(\mathrm{P}<0.05$, Table 1$)$. Thus, we found in the research that epidural use of bupivacaine in dogs has a beneficial effect on regenerative processes, reducing the healing time of wounds. In the study of blood parameters in dogs of the control group according to the results of clinical blood tests the number of leukocytes increased $(\mathrm{P}<0.01)$, which was a reaction to surgery, and the level of platelets on the third day after surgery decreased $(\mathrm{P}<0.01)$ by 2.87 times. Platelet counts differed between groups before surgery $(\mathrm{P}<0.01)$, after surgery $(\mathrm{P}<0.001)$, and three days after $(\mathrm{P}<0.001)$. This was most significantly manifested three days after surgery, when the level of platelets in the control group was the lowest for the entire study period. This can be interpreted as the body's response to the use of rimadyl, although bleeding was not observed in the animals and physiological hemostasis was maintained. Seven and ten days after surgery in the control group of animals the level of erythrocytes, hemoglobin and hematocrit decreased, which can be regarded as a reaction to surgery, although these indicators with their changes remained within the physiological norm. In the experimental group of animals only an increase $(\mathrm{P}<0.01)$ in the number of leukocytes three days after surgery was observed. Therefore, clinical analysis of blood showed that the postoperative period was more favourable in the group of animals which obtained bupivacaine (Table 2).

\section{Table 1}

Parameters of surgical wound healing in dogs after ovariohysterectomy with the use of two methods of analgesia $(n=10)$

\begin{tabular}{lcccc}
\hline $\begin{array}{c}\text { Parameters of surgical } \\
\text { wound healing }\end{array}$ & $\begin{array}{c}\text { Control, } \\
\mathrm{x} \pm \mathrm{SD}\end{array}$ & $\begin{array}{c}\text { Control, } \\
\mathrm{min}-\max \end{array}$ & $\begin{array}{c}\text { Experiment, } \\
\mathrm{x} \pm \mathrm{SD}\end{array}$ & $\begin{array}{c}\text { Experiment, } \\
\min -\max \end{array}$ \\
\hline $\begin{array}{l}\text { End of epithelialization } \\
\text { of the wound, day }\end{array}$ & $7.72 \pm 0.37$ & $6-9$ & $4.83 \pm 0.25^{* * * *}$ & $5-7$ \\
$\begin{array}{l}\text { Time of complete } \\
\text { wound healing, day }\end{array}$ & $10.24 \pm 0.25$ & $8-10$ & $7.07 \pm 0.26^{* * *}$ & $6-10$ \\
$\begin{array}{l}\text { Wound healing by } \\
\text { primary tension, } \%\end{array}$ & $76.5 \pm 1.5$ & $70-85$ & $82.5 \pm 1.7^{*}$ & $75-90$ \\
\hline
\end{tabular}

Note: ${ }^{*}-\mathrm{P}<0.05$ compared with the control group of animals with ANOVA.

Seven days after surgery the biochemical parameters in dogs (Table 3) of the control group showed a decrease $(\mathrm{P}<0.01)$ in urea level. The concentration of fibrinogen increased $(\mathrm{P}<0.01)$ three days after surgery in animals of both groups, which is typical for the acute inflammatory process which accompanies surgery.

Among the biochemical parameters in dogs the most important ones were the changes in the stress response. In dogs of the control group the glucose level almost doubled $(\mathrm{P}<0.001)$ immediately after surgery. During this period, in animals of the experimental group, the indicators differed $(\mathrm{P}<0.001)$ from those in the control group. Three days later this parameter in the control group decreased, which indicated the absence of a stress response in the subsequent period of research. The level of cortisol in the control group of animals did not change. Firstly, increased glucose level is an indicator of the stress response in animals in the immediate period after surgery; secondly, thiopental, which was used in the control group, has the ability to reduce blood flow in the liver and glomerular filtration rate. It also increases neuronal excitability, reduces glucose utilization by the brain and therefore, creates conditions for enhanced gluconeogenesis. Thus, the level of glucose was more informative for the assessment of metabolic response in dogs during surgery. In the experimental group of dogs the level of glucose and cortisol did not change. The established regularities indicate a qualitative antinociceptive effect of bupivacaine epidural administration in the experimental group of animals.

In the control group of dogs an increase in IL-1RA level after surgery $(\mathrm{P}<0.01)$, three $(\mathrm{P}<0.01)$ and seven $(\mathrm{P}<0.001)$ days after surgery was observed (Table 4). It was not detected in the experimental group, which indicated a lower intensity of inflammation in the experimental group of animals. IL-6 level after surgery increased $(\mathrm{P}<0.001)$ in the control group of animals, which indicated tissue damage in this period. In the experimental group of dogs seven days after surgery only an increase $(\mathrm{P}<0.05)$ of IL-4 level was found, and at this period differed $(\mathrm{P}<0.05)$ from the indicator in the control group, which confirms anti-inflammatory compensatory response in animals. The level of IL-1RA in the experimental group, compared with the control, was significantly lower: immediately after surgery -2.8 times $(\mathrm{P}<0.001)$, and on the third -2.4 times $(\mathrm{P}<$ $0.001)$ and the seventh -2.5 times $(\mathrm{P}<0.001)$. At the same time, seven days after surgery, the content of IL-4 in the experimental animals exceeded the control values by 1.9 times $(\mathrm{P}<0.01)$. 
Table 2

Hematological parameters of dogs after ovariohysterectomy with the use of two methods of anaesthesia and postoperative analgesia $(x \pm S D, n=5)$

\begin{tabular}{llccccc}
\hline \multicolumn{1}{c}{ Parameters } & Before surgery & After surgery & Three days after surgery & Seven days after surgery & Ten days after surgery \\
\hline \multirow{2}{*}{ Leukocytes, $10^{9} / \mathrm{L}$} & control & $13.1 \pm 1.89$ & $12.6 \pm 2.19$ & $20.8 \pm 0.77^{* *}$ & $12.7 \pm 1.94$ & $13.4 \pm 1.92$ \\
& experiment & $12.2 \pm 1.49$ & $10.8 \pm 0.98$ & $21.3 \pm 1.96^{* *}$ & $10.1 \pm 1.01$ & $9.8 \pm 1.27$ \\
\hline \multirow{2}{*}{ Lymphocytes, $10^{9} / \mathrm{L}$} & control & $2.74 \pm 1.05$ & $2.88 \pm 0.75$ & $3.51 \pm 0.86$ & $1.54 \pm 0.29$ & $2.43 \pm 0.71$ \\
& experiment & $3.07 \pm 1.24$ & $1.82 \pm 0.64$ & $3.74 \pm 1.24$ & $2.26 \pm 0.53$ & $1.52 \pm 0.32$ \\
\hline \multirow{2}{*}{ Monocytes, $10^{9} / \mathrm{L}$} & control & $0.62 \pm 0.13$ & $0.54 \pm 0.13$ & $0.52 \pm 0.12$ & $0.44 \pm 0.09$ & $0.54 \pm 0.09$ \\
& experiment & $0.54 \pm 0.09$ & $0.41 \pm 0.12$ & $0.52 \pm 0.11$ & $0.36 \pm 0.07$ & $0.47 \pm 0.07$ \\
\hline \multirow{2}{*}{ Granulocytes, $10^{9} / \mathrm{L}$} & control & $10.62 \pm 1.53$ & $9.13 \pm 1.55$ & $13.43 \pm 2.07$ & $10.85 \pm 1.84$ & $10.56 \pm 1.42$ \\
& experiment & $8.77 \pm 0.64$ & $8.54 \pm 0.73$ & $12.06 \pm 1.72$ & $7.61 \pm 0.54$ & $7.93 \pm 0.91$ \\
\hline \multirow{2}{*}{ Erythrocytes, $10^{12} / \mathrm{L}$} & control & $8.72 \pm 0.40$ & $8.73 \pm 0.53$ & $8.91 \pm 1.54$ & $7.08 \pm 0.26^{* *}$ & $6.52 \pm 0.17^{* * *}$ \\
& experiment & $6.94 \pm 0.36$ & $6.67 \pm 0.17$ & $7.94 \pm 1.07$ & $7.73 \pm 0.66$ & $6.74 \pm 0.42$ \\
\hline \multirow{2}{*}{ Hemoglobin, $\mathrm{g} / \mathrm{L}$} & control & $173.8 \pm 5.9$ & $173.0 \pm 7.3$ & $187.2 \pm 4.0$ & $139.2 \pm 3.9^{* *}$ & $143.2 \pm 5.3^{* *}$ \\
& experiment & $143.0 \pm 14.0$ & $138.8 \pm 10.9$ & $148.2 \pm 12.4$ & $163.4 \pm 24.0$ & $142.2 \pm 13.5$ \\
\multirow{2}{*}{ Hematocrit, $\%$} & control & $58.7 \pm 2.1$ & $58.3 \pm 3.6$ & $49.3 \pm 6.1$ & $45.7 \pm 0.9^{* * *}$ & $45.9 \pm 1.2^{* * * *}$ \\
& experiment & $47.4 \pm 4.1$ & $45.5 \pm 3.1$ & $47.1 \pm 2.5$ & $53.3 \pm 6.6$ & $46.4 \pm 4.2$ \\
\hline \multirow{2}{*}{ Platelets, $10^{9} / \mathrm{L}$} & control & $290 \pm 39$ & $232 \pm 48$ & $101 \pm 16^{* *}$ & $259 \pm 45$ & $250 \pm 78$ \\
& experiment & $445 \pm 36^{\circ *}$ & $415 \pm 43^{\circ 00}$ & $428 \pm 112^{\circ 00}$ & $430 \pm 106$ & $409 \pm 78$ \\
\hline
\end{tabular}

Note: ${ }^{* \circ}-\mathrm{P}<0.05,{ }^{*}{ }^{\circ}-\mathrm{P}<0.01,{ }^{* * * 00}-\mathrm{P}<0.001$ compared with indicators: $*$ - before surgery in control and experimental group, ${ }^{\circ}-$ control group compared with the experimental group within one column of table with the Bonferroni-corrected ANOVA.

Table 3

Biochemical parameters of blood and stress response indicators of dogs after ovariohysterectomy

with the use of two surgical anaesthesia schemes and postoperative analgesia $(x \pm S D, n=5)$

\begin{tabular}{|c|c|c|c|c|c|c|}
\hline \multicolumn{2}{|c|}{ Parameters } & Before surgery & After surgery & Three days after surgery & Seven days after surgery & Ten days after surgery \\
\hline \multirow{2}{*}{ Urea, mmol/L } & control & $6.68 \pm 0.38$ & $6.64 \pm 0.36$ & $6.04 \pm 0.58$ & $4.52 \pm 0.26^{* *}$ & $5.63 \pm 0.69$ \\
\hline & experiment & $5.54 \pm 0.73$ & $5.93 \pm 0.58$ & $4.92 \pm 0.57$ & $4.97 \pm 0.52$ & $4.62 \pm 0.74$ \\
\hline \multirow{2}{*}{ Creatinine, $\mu \mathrm{mol} / \mathrm{L}$} & control & $96.16 \pm 5.31$ & $96.93 \pm 3.89$ & $100.24 \pm 6.25$ & $86.81 \pm 5.83$ & $95.23 \pm 9.90$ \\
\hline & experiment & $84.94 \pm 9.04$ & $89.32 \pm 3.64$ & $86.26 \pm 6.92$ & $89.08 \pm 6.92$ & $83.97 \pm 9.57$ \\
\hline \multirow{2}{*}{ Glucose, $\mathrm{mmol} / \mathrm{L}$} & control & $4.05 \pm 0.28$ & $7.94 \pm 0.34 * * *$ & $4.23 \pm 0.30$ & $4.38 \pm 0.16$ & $4.06 \pm 0.13$ \\
\hline & experiment & $3.73 \pm 0.33$ & $4.36 \pm 0.65^{\circ 0 \circ}$ & $4.68 \pm 0.23$ & $4.52 \pm 0.21$ & $4.14 \pm 0.32$ \\
\hline \multirow{2}{*}{ Fibrinogen, $\mathrm{g} / \mathrm{L}$} & control & $2.21 \pm 0.20$ & $2.53 \pm 0.39$ & $3.81 \pm 0.27 * *$ & $3.22 \pm 0.38$ & $3.18 \pm 0.40$ \\
\hline & experiment & $2.14 \pm 0.53$ & $1.87 \pm 0.42$ & $4.34 \pm 0.50 * *$ & $3.05 \pm 0.61$ & $2.19 \pm 0.29$ \\
\hline \multirow{2}{*}{ Cortisol, nmol/L } & control & $278.5 \pm 36.50$ & $322.4 \pm 36.94$ & $305.8 \pm 60.30$ & $364.8 \pm 37.82$ & $368.8 \pm 59.18$ \\
\hline & experiment & $255.2 \pm 43.32$ & $362.6 \pm 51.29$ & $242.7 \pm 41.90$ & $219.8 \pm 34.90$ & $233.2 \pm 25.97$ \\
\hline
\end{tabular}

Note: see Table 2.

Table 4

The content of serum cytokines in the blood of dogs after ovariohysterectomy with the use

of two schemes of surgical anesthesia and postoperative analgesia $(x \pm S D, n=5)$

\begin{tabular}{|c|c|c|c|c|c|c|}
\hline \multicolumn{2}{|c|}{ Parameters } & Before surgery & After surgery & Three days after surgery & Seven days after surgery & Ten days after surgery \\
\hline \multirow{2}{*}{ IL-1RA, pg/mL } & control & $1230 \pm 138$ & $2874 \pm 379 * *$ & $2832 \pm 321 * *$ & $3062 \pm 296^{* * *}$ & $1124 \pm 304$ \\
\hline & experiment & $1208 \pm 212$ & $1044 \pm 121^{\circ 00}$ & $1159 \pm 110^{\circ 00}$ & $1240 \pm 126^{\circ 00}$ & $1081 \pm 153$ \\
\hline \multirow{2}{*}{$\mathrm{IL}-4, \mathrm{pg} / \mathrm{mL}$} & control & $15.34 \pm 2.43$ & $16.18 \pm 1.01$ & $17.53 \pm 2.69$ & $12.26 \pm 2.52$ & $10.72 \pm 1.67$ \\
\hline & experiment & $12.61 \pm 1.42$ & $11.27 \pm 1.27$ & $18.22 \pm 2.03$ & $23.48 \pm 3.38 * \circ$ & $11.18 \pm 2.21$ \\
\hline \multirow{2}{*}{$\mathrm{IL}-6, \mathrm{pg} / \mathrm{mL}$} & control & $10.12 \pm 1.34$ & $25.97 \pm 0.42 * * *$ & $11.87 \pm 3.11$ & $15.34 \pm 2.51$ & $12.62 \pm 1.29$ \\
\hline & experiment & $11.93 \pm 2.60$ & $17.74 \pm 4.67$ & $16.56 \pm 5.51$ & $17.73 \pm 3.44$ & $18.82 \pm 2.96$ \\
\hline
\end{tabular}

Note: see Table 2.

Thus, the cytokine profile study of the blood of dogs following ovariohysterectomy showed that the inflammation degree in the postoperative period depends on the type of surgical anaesthesia and postoperative analgesia. The suggested scheme of surgical local anaesthesia and postoperative analgesia with the use of bupivacaine causes a less pronounced inflammatory reaction compared with thiopenate anaesthesia and postoperative analgesia with the use of rimadyl.

Therefore, during the study of blood parameters in dogs definite regularities were found. Both anaesthesia-analgesia methods have their technical peculiarities and do not cause pathological changes in the metabolism, but the use of local anaesthetics affects the body of animals less.

\section{Discussion}

Methods of local anaesthesia are improved according to the principle of their complication and differentiation: new local anaesthetics appear, methods of performing blockades are improved, the selectivity of indications for certain methods of local anaesthesia increases. This is supposed to improve the effectiveness of medical care for animals. A wide range of drugs for anaesthesia, local anaesthesia, sedation and myorelaxation are used during surgical interventions in small animals. These drugs belong to different pharmacological groups and interrupt nociception at its different stages. This explains the variety of pharmacological agents that cause analgesia. Transduction is transmitted by $\mathrm{A} \delta$ and $\mathrm{C}$-fibers of peripheral nerves. It is suppressed by NSAIDs, opiates, local anaesthetics and corticosteroids. Transmission of pain stimuli from peripheral pain receptors to the spinal cord occurs through the primary afferent sensory nerve fibers. It is blocked by local anaesthetics and $\alpha^{2}$-agonists. Impulse modulation occurs in the spinal cord. It is suppressed by local anaesthetics, opiates, $\alpha^{2}$-agonists, NSAIDs, NMDA receptor antagonists, tricyclic antidepressants and anticonvulsants. The projection of impulses from the spinal cord to the brain is transmitted by nerve pathways - spino-thalamic, spinoreticular, spino-mesencephalic and spino-hypothalamic pathways. Perception is the integration and processing of nociceptive information in the brain in order to form a response through the descending nerve pathways in the spinal cord. Perception can be influenced by general anaesthetics, opiates, $\alpha^{2}$-agonists, benzodiazepines, and phenothiazines (Kerroll, 2009).

Taking into account the peculiarities of different drugs used in the research, the following aspects should be mentioned. Xylazine belongs to the group of $\alpha^{2}$-adrenoceptor agonists which affect the transmission, modulation and perception of nerve impulses. Its action is manifested by sedation, myorelaxation and analgesia. Unlike local anaesthetics, its anal- 
gesic effect is not associated with nerve fiber blockade. Thiopenate anaesthesia provides all clinical signs of general anaesthesia, causes central inhibition of antinociceptive impulses, but its action does not significantly affect the peripheral nervous system. It is known that thiopental has no analgesic properties, and its effect is manifested by the fact that it prolongs the period of opening GABA - dependent channels on the postsynaptic membranes of brain neurons, the time of release of chlorine ions into the nerve cell, resulting in hyperpolarization of membranes. This drug also inhibits the stimulating effect of amino acids (aspartate and glutamate). The use of thiopental promotes myorelaxation, suppressing polysynaptic reflexes, slows the conduction of impulses through the inserted neurons of the spinal cord, reduces metabolic processes in the brain, brain utilization of glucose and oxygen. Thiopental has a soporific effect, in particular accelerates the process of falling asleep and changes the sleep structure. This drug also depresses the respiratory center, reduces its sensitivity to carbon dioxide, causes cardiodepression, increases the capacity of the venous system, reduces hepatic blood flow and glomerular filtration rate.

The use of local anaesthetics affects the transduction, transmission and modulation of nerve impulses - the conduction of the impulse is blocked at the level of the roots of the spinal nerves and the great nerves until they leave the interciliary foramen. Due to this process, the reflex arc is interrupted, and the blockade of the elements of the peripheral nervous system provides a qualitative antinociceptive effect.

Although amides and esters belong to the same group of local anaesthetics, their metabolism is different. Novocaine, which is a chemical compound from a number of esters of para-aminobenzoic acid is metabolized in the animal by hydrolysis with plasma cholinesterase to para-aminobenzoic acid, which has antihistamine and antitoxic effects, and diethylaminoethanol, which has anaesthetic properties (Panko et al., 1994).

Amides are metabolized mainly in the liver of the animal under the influence of the cytochrome system. Lidocaine is the most common local amide anaesthetic used in modern anesthesiology, primarily due to its rapid onset of action and relatively low toxicity (Suslov et al., 2011). In terms of the ability to penetrate the nerve, lidocaine (Fesenko, 2002) is one of the drugs that penetrates the most distant components of the nerve plexuses under conduction anaesthesia.

Bupivacaine is almost completely metabolized in the liver by aromatic hydroxylation to 4-hydroxybupivacaine and N-dealkylation to 2,6-pipecoloxylidine, both of which are mediated by cytochrome P450 3A4. The clearance of these substances depends on hepatic perfusion and the activity of the metabolizing enzyme. Bupivacaine metabolites are neither active nor toxic. About 5-10\% of the substance is excreted in the active form in the urine. The use of high concentrations of bupivacaine $(0.50-0.75 \%)$ may be accompanied by a risk of both general and cardiotoxicity, which is widely described in the literature (Morgan et al., 2000; Campoy \& Read, 2013). But at the same time bupivacaine in a concentration of $0.2 \%$ has pronounced analgesic properties.

Taken into account the above mentioned data, we used a $2.0 \%$ lidocaine solution for surgical analgesia, which is less toxic than $0.5 \%$ bupivacaine. Lidocaine acts faster, its duration is shorter, but sufficient to perform planned surgeries, including ovariohysterectomy. $0.2 \%$ solution of bupivacaine used in the postoperative period shows faster analgesia, less toxicity compared to $0.5 \%$ solution, and a long shelf life. The use of catheter techniques and the use of the above drugs, in our opinion, provide optimal conditions for both surgical and postoperative analgesia. Similar drugs are used by domestic human anesthesiologists (Fesenko et al., 2007; Suslov et al., 2011). Therefore, we performed a scheme of aneasthesia during surgery, which used a $2 \%$ solution of lidocaine epidurally on the background of premedication with xylazine, and in the postoperative period a $0.2 \%$ solution of bupivacaine.

Traditionally, novocaine is used in veterinary medicine for therapeutic purposes as a means of pathogenetic therapy. The therapeutic properties of local anaesthetics of the amide series are used insufficiently, and it is possible that bupivacaine will be a drug that will provide a wide range of therapeutic effects for the treatment of diseases of non-communicable etiology in animals. Unlike novocaine, the therapeutic effect of bupivacaine is primarily associated with prolonged analgesia and changes in physiological parameters in the analgesic area. Prolonged analgesia can be achieved at least in two ways - by using a drug or long-acting treatment mixtures, and by improving the blockade technique. Recent studies indicate the viability of liposomal bupivacaine - a dosage form that provides a slow release of the active substance with liposomes. The dosage form is bupivacaine, enclosed in multivesicular liposomes. Each liposome consists of many chambers (vesicles) with hydrophilic nuclei which contain an anaesthetic. This form prolongs the action of bupivacaine for up to 72 hours. The concentration of liposomal bupivacaine in the blood has two peaks: the first one occurs approximately one hour after administration and corresponds to the systemic absorption of free bupivacaine in solution: the second peak (occurs after 12-36 hours) is the result of gradual release of anaesthetic from liposomal particles. The half-life of the drug is 13.4 31.4 hours depending on the administered dose (Chahar \& Cummings, 2012; Hu et. al., 2013; Burbridge \& Jaffe, 2015; Aggarwal, 2018; Discepola et al., 2020; Markova et al., 2020).

The choice of bupivacaine concentration can be also considered as an important aspect. Using this approach we can achieve either the loss of all types of sensitivity, or analgesia and pathogenetic therapeutic effects. Previously, in veterinary practice there was no clear division of conditions that cause local anaesthetics into those that are accompanied by loss of all types of sensitivity (anaesthesia), and those that eliminate pain sensitivity (analgesia). Currently, the introduction into clinical practice of long-acting amide local anaesthetics - bupivacaine and ropivacaine - provides the desired effect of anaesthesia or analgesia depending on the applied concentration of the drug. The analgesic effect of these drugs is also accompanied by pathogenetic therapeutic effects. As in this condition there is no motor component of the blockade, the animals retain motor function of the limbs. This method is called differential pharmacological blockade with local anaesthetics. It can be achieved by using a local long-acting anaesthetic, such as bupivacaine, and modern techniques that ensure the delivery of the drug to the elements of the peripheral nervous system. As it is a new direction in veterinary medicine, it needs a comprehensive study in terms of various aspects of action, which is actually presented in this article. And at clinical introduction of a new technique it is necessary to consider alternative methods of medical care and to compare their influence on the organism of animals considering the maximum number of factors. Therefore, performing differential blockade with $0.2 \%$ bupivacaine solution, we compared various aspects of this technique with an alternative method. Dogs underwent thiopental anesthesia with rimadyl analgesia during ovariohysterectomy.

As for the technical side of the blockade needle insertion and catheterization, using disposable kits proved to be convenient in terms of technique. "Perifix" kits have all the necessary technical means to ensure the effective implementation of blockades, including bacterial filters. For repeated administration of drugs epidurally in dogs in the postoperative period we used subcutaneous "tunneling" of the catheter. This causes limited aseptic inflammation of the tissues, but allows the catheter to be fixed securely. We did not find any complications from the technical aspects of the blockade.

Surgical wound healing in dogs after ovariohysterectomy with application of operative and postoperative local anaesthesia regenerative processes was faster than in animals treated with anaesthesia and rimadyl administered after surgery. In the animals of the experimental group better dynamics of reparative processes were observed, which were manifested by earlier wound filling with epithelial tissue and complete wound healing. Thus, the use of operative and postoperative epidural anaesthesia in dogs accelerates tissue regeneration, balances the inflammatory response in the wound and accelerates the formation of tissue in the surgical wound, compared with animals of the control group. Our data coincides with the results of other researchers concerning positive aspects of local anaesthetics use and also confirms the superiority of complex treatment methods over local ones (Rublenko \& Vlasenko, 2001; Rublenko et al., 2014).

Clinical blood indicators, biochemical parameters of serum and plasma, namely: integrated indicators of protein metabolism, the absence of renal failure symptoms, markers of stress body reactions were determined to define the influence of surgical anaesthesia and postoperative analgesia on the dogs' health, including the therapeutic effect of bupivacaine epidural administration. Taking into account the fact that blockades also have antiinflammatory effect, this influence can be assessed by determining the level of interleukins - non-specific mediators of inflammation. Thus, IL- 
1RA is a physiological regulator of IL-1 expression. IL-1RA is an important natural anti-inflammatory protein, the absence or low content of which plays a significant role in the pathogenesis of numerous diseases, such as rheumatoid arthritis, colitis, osteomyelitis, periostitis. Binding to the interleukin-1 receptor, the antagonist prevents the activation of the intracellular signal cascade of this proinflammatory cytokine. In healthy tissue IL-1RA is synthesized to prevent IL-1 mediated inflammatory reactions. In case of an uncontrolled inflammatory reaction, the level of the receptor antagonist to interleukin-1 is insufficient to regulate its activity. IL-1RA effect as a non-steroidal anti-inflammatory drug can be used in the treatment of chronic inflammatory diseases. IL -4 belongs to the hematopoietins group and acts with the help of specific receptors on $\mathrm{T}$ and $\mathrm{B}$ cells, macrophages, liver cells, muscle and fibroblasts. This interleukin has the ability to stimulate cellular and humoral immunity.

IL-6 is involved in the differentiation of B lymphocytes, their maturity and transformation into plasma cells that secrete immunoglobulins and facilitate the expression of receptors for other interleukins, in particular IL-2 and the formation of $\mathrm{T}$ cells. It is a powerful factor in the growth and differentiation of $\mathrm{B}$ cells and plays a significant role in the growth of tumour cells, so its inhibition can even have antitumour effect. Therefore, the peculiarities of mentioned above interleukins make it relevant to determine their level in the assessment of the degree and dynamics of the inflammatory process, in particular during surgery.

In dogs of the control group, the number of leukocytes increased, which was a reaction to surgery, and the platelets level on the third day after surgery was lower. Platelet count decreased by $65.1 \%$ at that time, although no bleeding was observed in animals. According to the literary sources, physiological hemostasis is preserved when the number of platelets in the dogs' blood is 100-150 10\%/L (Lamont \& Lemke, 2008). Nonsteroidal anti-inflammatory drug rimadyl was administered for three days and three days later thrombocytopenia was diagnosed. This can be considered as a reaction of the body to its use. In the control group of animals the level of erythrocytes and hematocrit seven days after surgery also changed. It can also be regarded as a reaction to the manipulations, although these indicators were within the physiological norm. In the experimental group only, an increase in the number of leukocytes three days after surgery was found. Thus, clinical blood test showed that the postoperative period was more favourable in the group of animals that received bupivacaine after surgery. Seven days after surgery, dogs of the control group had a decrease in urea level. The concentration of fibrinogen increased three days after surgery in animals of both groups. It is typical for the acute inflammatory process that accompanies surgery.

Among the biochemical parameters of blood, the most important ones were stress response changes. In dogs of the control group the glucose level almost doubled immediately after surgery. Three days later this parameter decreased indicating the absence of a stress response in the later period of the research. The level of cortisol in the control group of animals did not change. Firstly, elevated glucose level is an indicator of a stress response in the immediate period after surgery; secondly, thiopental, which was used in the control group has the ability to reduce blood flow in the liver and glomerular filtration rate. It increases the degree of neuronal excitability, reduces glucose utilization by the brain and thus creates conditions for enhanced gluconeogenesis. All these factors caused hyperglycemia in the control group of animals. According to Kerroll (2009), thiopental does not directly affect renal and hepatic function, but it can have a negative influence on hemodynamics and weaken the function of these organs.

Thus, glucose level was a more informative indicator of the metabolic response in dogs during surgery under barbiturate anesthesia. Therefore, the results of our research confirm the data by Fesenko (2010), who considers glucose to be a more sensitive stress marker than cortisol.

In the experimental group of dogs, glucose and cortisol levels did not change. The determined regularities indicate a qualitative antinociceptive effect of bupivacaine epidural administration in the experimental group of animals. The conducted anaesthesia-analgesia scheme did not affect the glucose and cortisol levels, which reflected stress response level in the animals throughout the research period. Thus, the use of local anaesthetics has less stress effect on the body of dogs than thiopenate anaesthesia and the use of rimadyl for analgesic purposes after surgery.
In the control group of dogs, an increase in the IL-1RA level three and seven days after surgery was observed. Elevated IL-RA level limits IL-1 synthesis in the case of inflammation and an excess of proinflammatory interleukin IL-1 in the body can cause pathological changes in organs and tissues (Shhekyna et al., 2013). Therefore, if the IL-RA level does not increase, the inflammation intensity in the body is lower. An increase in IL-RA was observed in the control group of dogs and was not detected in the experimental group, which indicated lower inflammation intensity in the experimental group of animals. Similar phenomena with the application of epidural bupivacaine, which reduces the inflammatory reaction intensity were described by Docenko (2011), who studied the IL-1 level in the postoperative period. After surgery, the IL- 6 level increased in the control group of animals, which indicated tissue damage during this period, as IL-6 enhances protein synthesis in the "acute phase" of inflammation (Kibkalo, 2017). In the experimental group of dogs seven days after surgery only an increase in the IL-4 level was found. IL-4 increase in blood serum confirms the anti-inflammatory compensatory response in animals. This interleukin reduces the production of inflammatory mediators, some proteases, inhibits T lymphocytes activation and reduces IL-1 production (Filipenko et al., 2012). Thus, our study of the cytokine profile of dogs' blood on the background of ovariohysterectomy showed that the inflammation degree in the postoperative period depends on the type of surgical anaesthesia and postoperative analgesia.

\section{Conclusion}

In the process of performing ovariohysterectomy in dogs a positive role of local anaesthetics for analgesia and pathogenetic treatment, in particular $0.2 \%$ bupivacaine solution as a drug for epidural blockade in dogs, was determined. We introduced a scheme of anaesthesia during surgery in dogs, which used a $2 \%$ solution of lidocaine epidurally on the background of premedication with xylazine, and in the postoperative period $-0.2 \%$ solution of bupivacaine. Wound healing in dogs after ovariohysterectomy treated with local anaesthaesia and postoperative analgesia with $0.2 \%$ bupivacaine solution was faster compared with thiopental anaesthesia and rimadyl analgesia.

In dogs after ovariohysterectomy the dynamics of changes in morphological and biochemical parameters of blood under the influence of local anaesthesia and analgesia with bupivacaine was manifested only after three days by an increase in leukocytes and fibrinogen, while under the influence of thiopental anaesthesia and analgesia the level of erythrocytes, leukocytes, platelets and fibrinogen increased, compared with the data before analgesia. Seven days after surgery in the control group of animals normalization of these indicators with a urea decrease was observed.

In dogs which had undergone ovariohysterectomy, local anaesthesia and analgesia with bupivacaine were not accompanied by changes in the level of stress markers - glucose and cortisol, in contrast to anaesthesia and analgesia with rimadyl, when glucose level increased.

Local anaesthesia and analgesia with bupivacaine for ovariohysterectomy in contrast to anaesthesia and analgesia with rimadyl reduced the intensity of the inflammatory reaction in dogs, accompanied by an increase in anti-inflammatory interleukin 4 (IL-4) only on the seventh day, with the absence of IL-1RA and IL- 6 changes, while under anaesthesia the level of anti-inflammatory receptor antagonist interleukin-1 (IL-1RA) after three and seven days increased, and the level of pro-inflammatory interleukin 6 (IL-6) after surgery increased.

\section{References}

Aggarwal, N. (2018). Local anesthetics systemic toxicity association with exparel (bupivacaine liposome) - a pharmacovigilance evaluation. Expert Opinion in Drug Safety, 17(6), 581-587.

Bahrenberg, A. I., Dzikiti, B. T., Fosgate, G. T., Stegmann, F. G., Tacke, S. P., \& Rioja, E. (2015). Antinociceptive effects of epidural magnesium sulphate alone and in combination with morphine in dogs. Veterinary Anaesthesia and Analgesia, 42(3), 319-328.

Bomberg, H., Kubulus, C., Herberger, S., Wagenpfeil, S., Kessler, P., Steinfeldt, T., Standl, T., Gottschalk, A., Stork, J., Meissner, W., Birnbaum, J., Koch, T., Sessler, D. I., Volk, T., \& Raddatz, A. (2016). Tunnelling of thoracic epidural cathe- 
ters is associated with fewer catheter-related infections: A retrospective registry analysis. British Journal of Anaesthesia, 116(4), 546-553.

Burbridge, M., \& Jaffe, R. A. (2015). Exparel ${ }^{\circledR}$ : A new local anesthetic with specia safety concerns. Anesthesia and Analgesia, 121(4), 1113-1114.

Butterworth, J. F. (2010). Models and mechanisms of local anesthetic cardiac toxicity: A review. Regional Anesthesia and Pain Medicine, 35(2), 167-176.

Campoy, L., \& Read, M. R. (2013). Small animal regional anaesthesia and analgesia. Wiley-Blackwell, Ames, Chichester, Oxford.

Carregaro, A. B., Freitas, G. C., Lopes, C., Lukarsewskic, R., Tamiozzoc, F. S., \& Santosc, R. R. (2016). Evaluation of analgesic and physiologic effects of epidural morphine administered at a thoracic or lumbar level in dogs undergoing thoracotomy. Veterinary Anaesthesia and Analgesia, 41(2), 205-211.

Chahar, P., \& Cummings, K. C. (2012). Liposomal bupivacaine: A review of a new bupivacaine formulation. Journal of Pain Research, 5, 257-264.

Discepola, P., Bouhara, M., Kwon, M., Siddiqui, B. A., Whitwell, T. A., Sanghvi, S. Y., Cook, K. D., Moore, R. E., Korban, A., \& Eloy, J. D. (2020). Exparel ${ }^{1 /}$ (Long-acting liposomal bupivacaine) use for popliteal nerve block in postoperative pain control after ankle fracture fixation. Pain Research and Management, 2020, 5982567

Docenko, V. V. (2011). Vlijanie razlichnykh metodik anestezii na vyrazhennost' vospalitel'nogo otveta pri operacijah v plasticheskoj hirurgii [Influence of various anesthesia techniques on the severity of the inflammatory response during plastic surgery operations]. Ukrajins'kyj Zhurnal Ekstremal'noji Medycyny imtys G. O. Mozhaeva, 12(3), 55-59 (in Russian).

Epstein, M., Rodan, I., Griffenhagen, G., Kadrlik, J., Petty, M., Robertson, S., \& Simpson, W. (2015). AAHA/AAFP pain management guidelines for dogs and cats. Journal of the American Animal Hospital Association, 51(2), 67-84

Fesenko, V. S. (2002) Blokady nerviv [Nerve blockades]. Ekskliuzyv, Kharkiv (in Ukrainian).

Fesenko, V. S. (2010). Topografo-anatomichne ta klinichne obgruntuvannia pidvyshhennja efektyvnosti ta bezpechnosti regionamogo zneboljuvannja [Topographic-anatomical and clinical substantiation of increase of efficiency and safety of regional anesthesia]. Navchalno-Naukovyi Vydavnycho-Polihrafichnyi Tsentr KhNURE, Dnipropetrovsk (in Ukrainian).

Fesenko, V. S., Donchak, J. D., Perepelica, E. E., \& Rudachenko, O. J. (2007) Intoksikacija bupivakainom: Opisanie sluchaja i literaturnyj obzor [Bupivacaine ntoxication: Case description and literature review]. Medicina Neotlozhnyh Sostojanij, 6(13), 90-94 (in Russian).

Filipenko, V. A., Leont'jeva, F. S., Morozenko, D. V., \& Korzh, I. V. (2012). Vmist cytokiniv u syrovatci krovi hvoryh na osteoartroz [The content of cytokines in the serum of patients with osteoarthritis]. Ortopedyja, Travmatologyja y Protezyrovanye, 3, 52-55 (in Ukrainian).

Ghadirian, S., Vesal, N., Maghsoudi, B., \& Akhlagh, S. H. (2016). Comparison of lidocaine, lidocaine-morphine, lidocaine-tramadol or bupivacaine for neura blockade of the brachial plexus in fat-tailed lambs. Veterinary Anaesthesia and Analgesia, 43(1), 109-116.

Grubb, T., \& Lobprise, H. (2020). Local and regional anaesthesia in dogs and cats: Overview of concepts and drugs (Part 1). Veterinary Medicine and Science, 6 , 209-217.

Gutierrez-Blanco, E., Victoria-Mora, J. M., Ibancovichi-Camarillo, J. A., Sauri-Arceo, C. H., Bolio-González, M. E., Acevedo-Arcique, C. M., Cano, G. M., \& Steagall, P. V. M. (2015). Postoperative analgesic effects of either a constant rate infusion of fentanyl, lidocaine, ketamine, dexmedetomidine, or the combination lidocaine-ketamine-dexmedetomidine after ovariohysterectomy in dogs. Veterinary Anaesthesia and Analgesia, 42(3), 309-318.

Hansen, B., Lascelles, B. D., Thomson, A., \& De Puy, V. (2013). Variability of performance of wound infusion catheters. Veterinary Anaesthesia and Analgesia, 40(3), 308-315.

Hu, D. D., Onel, E., \& Singla, N. (2013). Pharmacokinetic profile of liposome bupivacaine injection following a single administration at the surgical site. Clinica Drug Investigation, 33, 109-115.

Johns, J., Harrison, T. K., Steffel, L., Howard, S. K., Kim, T. E., Kou, A., \& Mariano, E. R. (2014). A pilot in vitro evaluation of the "air test" for perineural catheter tip localization by a novice regional anesthesiologist. Joumal Ultrasound Medicine, $33,2197-2200$

Kalchofner Guerrero, K. S., Reichler, I. M., Schwarz, A., Jud, R. S., Hässig, M., \& Bettschart-Wolfensberger, R. (2014). Alfaxalone or ketamine-medetomidine in cats undergoing ovariohysterectomy: A comparison of intra-operative parameters and post-operative pain. Veterinary Anaesthesia and Analgesia, 41(6), 644-653.

Kerroll, G. L. (2009). Anesteziologija i anal'gezija melkih domashnih zhivotnyh [Small animal anesthesiology and analgesia]. Akvarium-Print, Moscow (in Russian).

Kibkalo, D. V. (2017). Analiz cytokinovogo statusu syrovatky krovi koriv za subklinichnoi' formy ketozu [Analysis of cytokins status in blood serum of cows with subclinical form of of ketosis]. Biologija Tvaryn, 19(3), 51-54 (in Ukrainian).

Koch, T., Sessler, D. I., \& Volk, T. (2016). Tunnelling of thoracic epidural catheters is associated with fewer catheter-related infections: A retrospective registry analysis. British Journal of Anaesthesia, 116(4), 546-553.
Lamont, L. A., \& Lemke, K. A. (2008). The effects of medetomidine on radial nerve blockade with mepivacaine in dogs. Veterinary Anaesthesia and Analgesia, $35(1), 62-68$.

Markova, L., Umek, N., Horvat, S., Hadžić, A., Kuroda, M., Pintarič, T. S., Mrak, V., $\&$ Cvetko, E. (2020). Neurotoxicity of bupivacaine and liposome bupivacaine after sciatic nerve block in healthy and streptozotocin-induced diabetic mice. BMC Veterinary Research, 16(1), 247

Marzok, M. A., \& Elkhodery, S. A. (2015). Comparative analgesic and sedative effects of tramadol, tramadol-lidocaine and lidocaine for caudal epidural analgesia in donkeys (Equus asinus). Veterinary Anaesthesia and Analgesia, 42(2), 215-219.

Mastrocinque, S. I., \& Fantoni, D. T. (2003). A comparison of preoperative tramadol and morphine for the control of early postoperative pain in canine ovariohysterectomy. Veterinary Anaesthesia and Analgesia, 30(4), 220-228.

Morgan Jr., G. E., \& Maged, S. M. (2000). Klinicheskaja anesteziologija [Clinical Anesthesiology]. Binom Nevskij Dialekt, Moscow, Sankt-Peterburg. Vol. 1 (in Russian)

Orlov, G. S. (2011). Lechebnye medikamentoznye blokady v travmatologii i ortopedii [Therapeutic drug blockade in traumatology and orthopedics]. Medicina Neotlozhnyh Sostojanij, 32-33, 30-33 (in Russian).

Otero, P. E., Verdier, N., Ceballos, M. R., Tarragona, L., Flores, M., \& Portela, D. A (2014). The use of electrical stimulation to guide epidural and intrathecal needle advancement at the L5-L6 intervertebral space in dogs. Veterinary Anaesthesia and Analgesia, 41(5), 543-547.

Otero, P. E., Zaccagnini, A. S., Fuensalida, S. E., Verdier, N., Sclocco, M., \& Portela, D. A. (2014). Use of electrical nerve stimulation to monitor lumbosacral epidural needle placement in cats. Veterinary Anaesthesia Analgesia, 41(3), 325-329.

Panko, I. S., Vlasenko, V. M., \& Levchenko, V. I. (1994). Patogenetychna terapija pry zapal'nyh procesah u tvaryn [Pathogenetic therapy in inflammatory processes in animals]. Kyiv (in Ukrainian).

Rioja, G. E. (2015). Local anesthetics. In: Grimm, K. A., Lamont, L. A., Tranquilli, W. J., Greene, S. A., \& Robertson, S. A. (Eds.). Veterinary anesthesia and analgesia: The fifth edition of lumb and jones. John Wiley \& Sons, Ames. Pp. 332-354.

Romano, M. Portela, D. A Breghi, G., \& Otero, P. E. (2016). Stress-related biomarkers in dogs administered regional anaesthesia or fentanyl for analgesia during stifle surgery. Veterinary Anaesthesia and Analgesia, 43(1), 44-54.

Rublenko, M. V. Andrijec, V. G., \& Berezovs'kyj, A. V. (2014). Kompleksnyj metod likuvannja nekrobakterioznyh urazhen' kincivok u velykoji rogatoji hudoby [A comprehensive method of treatment of necrobacterial lesions of the extremities in cattle]. Naukovyj Visnyk Veterynarnoji Medycyny, 108, 194-197 (in Ukrainian).

Rublenko, M. V., \& Vlasenko, S. A. (2001). Kompleksnyj metod likuvannja gnijnonekrotychnyh urazhen' diljanky pal'cia u koriv [A comprehensive method of treatment of purulent-necrotic lesions of the finger in cows]. Naukovyj Visnyk Nacional'nogo Agramogo Universytetu, 38, 54-57 (in Ukrainian).

Sarotti, D., Rabozzi, R., \& Franci, P. (2015). Comparison of epidural versus intrathecal anaesthesia in dogs undergoing pelvic limb orthopaedic surgery. Veterinary Anaesthesia and Analgesia, 42(4), 405-413.

Senera, A., Erkinb, Y., \& Senerc, A. (2015). In vitro comparison of epidural bacteria filters permeability and screening scanning electron microscopy. Brazilian Journal of Anesthesiology, 65(6), 491-496.

Shhekyna, K. G., Shtrygol', S. J., \& Drogovoz, S. M. (2013). Dosiagnennia ta perspektyvy cytokinovoji ta antycytokinovoji terapiji [Achievements and prospects of cytokine and anticytokine therapy]. Naukovyj Zhurnal MOZ Ukrajiny, 1(2), 121-129 (in Ukrainian).

Sljusarenko, D. V., Il'nic'kyj, M. G., \& Segodin, O. B. (2016). Porivnjal'na harakterystyka zbudlyvosti tkanyn u sobak za epidural'noji anesteziji $0.2 \%$ bupivakajinom, sedaciji ksylazynom ta tiopenatovogo narkozu [Comparative characteristics of tissue excitability in dogs under epidural anesthesia with $0.2 \%$ bupivacaine, sedation with xylazine and thiopenate anesthesia]. Naukovo-Tehnichnyj Biuleten' Naukovo-Doslidnogo Centru Biobezpeky ta Ekologichnogo Kontroliu Resursiv APK Dnipropetrovs'kogo Derzhavnogo Agrarno-Ekonomichnogo Universytetu, 4(3), 25-28 (in Ukrainian).

Snyder, L. B., \& Snyder, C. J. (2016). Effects of buprenorphine added to bupivacaine infraorbital nerve blocks on isoflurane minimum alveolar concentration using a model for acute dental/oral surgical pain in dogs. Journal of Veterinary Dentistry, 33(2), 90-96.

Son, W. G., Jang, M., Jo, S. M., Yoon, J., \& Leea, I. (2015). The volume effect of lidocaine on thoracic epidural anesthesia in conscious Beagle dogs. Veterinary Anaesthesia and Analgesia, 42(4), 414-424.

Son, W. G., Jang, M., Yoon, J., Lee, L. Y., \& Leea, I. (2014). The effect of epidural injection speed on epidural pressure an distribution of solution in anesthetized dogs. Veterinary Anaesthesia and Analgesia, 41(5), 526-533.

Subbotin, V. M., Subbotina, S. G., \& Aleksandrov, I. D. (2000). Sovremennye lekarstvennye sredstva $\mathrm{v}$ veterinarii [Modern medicines in veterinary medicine]. Feniks, Rostov-na-Donu (in Russian).

Suslov, V. V., Hizhnjak, A. A., \& Tarabrin, O. A. (2011). Epidural'naja anestezija analgezija [Epidural anesthesia and analgesia]. Sim, Kharkov (in Russian) 
Trabelsi, B., Charfi, R., Bennasr, L., Ben Marzouk, S., Eljebari, H., Jebabli, N., Ben Sassi, M., Trabelsi, S., \& Maghrebi, H. (2017). Pharmacokinetics of bupivacaine after bilateral ultrasound-guided transversus abdominis plane block following cesarean delivery under spinal anesthesia. International Journal of Obstetric Anesthesia, 32, 17-20.

Viscasillas, J., Sanchis, S., \& Sneddon, C. (2014). Ultrasound guided epidural catheter placement in a dog. Veterinary Anaesthesia And Analgesia, 41(3), 330-331.

Vlasenko, V. M., \& Tyhonjuk, L. A. (2000). Veterynarna anesteziologija [Veterinary anesthesiology]. Bilotserkivskyi Derzhavnyi Ahramyi Universytet, Bila Cerkva (in Ukrainian).

Wagatsuma, J. T., Deschk, M., Floriano, B. P., Ferreira, J. Z., Fioravanti, H., Gasparello, I. F., \& Oliva, V. N. L. S. (2014). Comparison of anesthetic efficacy and adverse effects associated with peribulbar injection of ropivacaine performed with and without ultrasound guidance in dogs. American Joumal of Veterinary Research, 75(12), 1040-1048.

Wakoff, T. I., Mencalha, R., Souza, N. S., Santos Sousa, C. A., Inácio Sousa, M. D., \& Scherer, P. O. (2014). Bupivacaine $0.25 \%$ versus ropivacaine $0.25 \%$ in brachial plexus block in dogs of beagle breed. Schearer Ciências Agrárias, Londrina, 34(3), 1259-1272.

Wendt-Hornickle, E., \& Snyder, L. B. (2016). Comparison of anesthesia with a morphine-lidocaine-ketamine infusion or a morphine-lidocaine epidural on time to extubation in dogs. Veterinary Anaesthesia and Analgesia, 43, 86-90. 